\title{
Motivações para o desenvolvimento profissional docente em comunidade com postura investigativa
}

\author{
Motivations for the teacher professional development in a \\ communities with inquiry stance
}

Carlos Jose Trindade Da Rocha ${ }^{1}$

\section{Resumo}

Este estudo objetiva analisar fatores motivacionais para o desenvolvimento profissional docente - DPD na educação científica. Para isso, realizou-se um estudo de caso com abordagem qualitativa, envolvendo cinco professores mestrandos e licenciados plenos em ciências naturais. A esses professores, foi enviado, via e-mail, um questionário com perguntas acerca de suas identificações pessoais, profissionais e motivacionais (baseadas em Likert). A partir dos resultados, foi identificado como os fatores motivacionais são concebidos pelos professores pesquisados. Os resultados identificam que os professores possuem autonomia e eficácia ao buscarem DPD como processo contínuo de profissionalidade e base estruturante de identidade e práticas pedagógicas em suas formações como profissionais da educação. Portanto, os professores possuem capacidade de se motivarem e de se organizarem em comunidades com posturas investigativas (Clube de Ciências), mesmo sem apoio das instituições públicas e da universidade, desenvolvendo com esforço e potencializando processos de transformação profissional para educação científica.

Palavras-Chave: Motivação. Desenvolvimento Profissional. Comunidade investigativa.

\begin{abstract}
This study aims to analyze motivational factors for teacher professional development - TPD in scientific education. For this, a case study with a qualitative approach was carried out with five master's and full-time graduates in the natural sciences. To these teachers, questions were sent via e-mail with questions about personal, professional and motivational identifications (based on Likert). From the results, were identified how the motivational factors are conceived by the teachers surveyed. The results

\footnotetext{
${ }^{1}$ Doutorando em Ensino de Ciências e Matemática - IEMCI/UFPA . Possui graduação em Licenciatura Plena em Ciências Naturais/Química pela Universidade do Estado do Pará (2003), Especialista em Metodologia Científica - UCAM/RJ (2005) e Especialista em Educação Social para Juventude - UEPA/UFPA (2013), Mestrado em Ciência de la Educación pela Universidade Autonoma de Asunción (2011) e Mestre em Ensino, História e Filosofia das Ciências e Matemática pela Universidade Federal do ABC (2015). E-mail: carlosjtr@hotmail.com.
}

Interfaces da Educ., Paranaiba, v.9, n.27, p. 157-183, 2018 
identify that teachers have autonomy in seeking TPD, since they understand it as a continuous process of professionalism and a structuring basis for the formation of the individual. Therefore, teachers have the capacity to motivate themselves and to organize themselves in local communities of study and research, even without the support of public institutions and the university, developing with effort and autonomy the effectiveness of training, and also, education.

Keywords: Motivation. Professional development. Inquiry stance.

\section{Introdução}

Este estudo faz parte de uma pesquisa maior em andamento e que, em parte, será tratada neste trabalho. Em nossa realidade, observamos, dentre outras variáveis, os fatores motivadores que levam os professores do ensino de Ciências Naturais a buscarem desenvolvimento profissional docente, em comunidades com postura investigativa, como no caso de um Clube de Ciências.

Por essa razão, esta pesquisa visa identificar fatores motivacionais, para compreender a evolução profissional de professores que desenvolvem trabalhos no Clube de Ciências "Prof. Dr. Cristovam Diniz", da Universidade Federal do Pará/Campus Castanhal, que vem se configurando como um espaço aberto para formação inicial e continuada de professores, contribuindo para transformação docente. Tal Clube, dentro de sua atuação, oferece um ambiente contínuo, que se complementa dentro de pressupostos da ideia de crescimento, evolução e ampliação das possibilidades de atuação de professores (MALHEIRO, 2016; ROCHA \& MALHEIRO, 2017a).

Dessa forma, o objeto desta investigação gira em torno de fatores motivadores para o Desenvolvimento Profissional Docente (DPD) em Clubes de Ciências, como comunidade investigativa. É fato que, na atualidade e nesta perspectiva, falta uma agenda de pesquisa sobre o docente nesses espaços. Assim, em razão do nosso envolvimento com o DPD, decidimos situar diferentes fatores que contribuem para esse direcionamento.

Ressalta-se que a preocupação de alguns autores (ALARCÃO, 1998; AZEVEDO \& CUNHA, 2014; FIORENTINI, 2011; MIZUKAMI, 2010; VAILLANT \& MARCELO, 2012) com a formação e o DPD cresce nos meios 
educativos, o que é atestado pelo aumento de produções científicas em periódicos e eventos relacionados ao tema. Nessa nova e fecunda perspectiva, encontramos algumas temáticas de formação baseadas no ensino investigativo (FIORENTINI, 2010), sendo realizadas em espaços não formais de educação científica - Clubes de Ciências.

Para Vaillant e Marcelo (2012), o DPD, associado a espaços não formais de educação científica, é uma ferramenta imprescindivel para melhoria do ensino de ciências. Assim, os autores destacam que se está longe dos momentos nos quais se pensava que a bagagem de conhecimentos adquiridos na formação inicial docente, unida ao valor da experiência como fonte de aprendizagem na prática, podia ser suficiente para exercer o trabalho docente no ensino das ciências.

Para Rocha (2015), acentuam-se, na atualidade, as exigências de que professor busque uma eficácia de formação ampla e holística, para entender as relações entre ambientes marcados por interações e reciprocidades, que não podem ser estudadas de maneira isolada. O DPD, longe de ser uma questão ocasional, transformou-se em uma necessidade de qualquer profissional, devido às vertiginosas mudanças que estão sendo produzidas na sociedade.

Pretendemos, com esta análise, responder à questão: de que maneira fatores motivadores são concebidos por mestrandos na condução para o DPD, com postura investigativa, em um Clube de Ciências, como comunidade investigativa?

Portanto, esta pesquisa tem o intuito de investigar, refletir e identificar fatores motivacionais para o DPD, com o fim de conhecer de perto a problemática que envolve o tema. Porém, antes de dar início a esta análise, tecemos, inicialmente, algumas considerações acerca de DPD e o Clube de Ciências. Além disso, descrevemos os procedimentos metodológicos e os resultados e implicações do objeto de estudo com os professores participantes desta pesquisa.

\section{Desenvolvimento profissional docente}


Nas últimas décadas, estudos têm chamado a atenção para o DPD em comunidades de prática (COCHRAN-SMITH \& LYTLE, 2002; CRECCI \& FIORENTINI, 2013; FIORENTINI, 2011; VAILLANT \& MARCELO, 2012, VAILLANT, 2010). Cocharan-Smith e Lytle (2002) apontam que a noção de comunidade tem sido usada de diferentes modos na teoria e na pesquisa educacional.

Da mesma forma, são utilizados muitos termos para se referir aos processos de aprendizagem que os docentes desenvolvem ao longo de sua vida ativa. A expressão DPD corresponde a outros termos que são utilizados com frequência: formação permanente, formação contínua, formação em serviço, reciclagem ou capacitação (VAILLANT \& MARCELO, 2012).

No entanto, concebemos, como Vaillant e Marcelo (2012), que a noção de desenvolvimento profissional melhor se adapta à concepção do docente como profissional do ensino. Pois isso dá uma noção de desenvolvimento como uma conotação de evolução e continuidade, que supera a tradicional justaposição entre formação inicial e aperfeiçoamento dos docentes.

Nessa perspectiva, os membros de uma comunidade, em geral, trocam significados e ideias sobre o empreendimento em que são engajados. Assim, a aprendizagem, tomando por base os estudos de Lave e Wenger (1991), ocorre mediante participação em comunidades de prática investigativa, como um fenômeno social carregado de ideologia e valores e que emerge da participação direta em uma prática social, independente de esta ser organizada com o propósito de ensinar algo a alguém (CRECCI \& FIORENTINI, 2013; FIORENTINI, 2010).

Fiorentini (2010, p. 583), ao discutir o DPD em grupo colaborativo, afirma, apoiado em seus estudos, que é na "participação nas práticas reflexivas e investigativas do grupo que os professores tornam-se membros, legítimos da comunidade profissional, sendo o desenvolvimento profissional e a melhoria de sua prática docente uma consequência dessa participação”.

Rocha (2015, p. 90), por sua vez, concebe o DPD como um processo que envolve concepções múltiplas de se refletir a própria prática, "fazer e saber por que está se fazendo" algo e também não perder o espírito científico 
e a eficácia ao longo da profissão. O autor destaca que é um processo dinâmico, que pode assumir um duplo caminho: um, no qual o sucesso atingido pelo professor pode levá-lo a uma constante "busca" em seu aprimoramento e desenvolvimento profissional; e o outro, no qual, seu fracasso pode até mesmo fazê-lo abandonar a profissão ou permanecer numa situação de "inércia" frente aos compromissos e comprometimentos com a educação (p. 20).

Neste sentido, ao situar o DPD e a aprendizagem docente em comunidades, Crecci e Fiorentini (2013) descrevem que trabalhar com uma postura investigativa envolve um processo contínuo de problematização e deliberação no cotidiano escolar. O trabalho dos professores consiste em participar de mudanças educacionais e sociais, tendo por base um processo contínuo, colaborativo e crítico de analisar dados da prática, questionar e utilizar criticamente resultados de estudos acadêmicos relativos à prática de ensinar e aprender.

\section{Clube de Ciências Prof. Dr. Cristovam Diniz como Comunidade Investigativa}

Com base nas análises de DPD em comunidades com postura investigativa, concebe-se que o Clube de Ciências "Prof. Dr. Cristovam W. P. Diniz", na Universidade Federal do Pará - UFPA/Campus Castanhal, é um ambiente alternativo, destinado, especificamente, para o ensino, pesquisa e extensão de ações didáticas voltadas às Ciências e Matemáticas, almejando a popularização da ciência, a iniciação científica infanto-juvenil e a formação inicial e continuada de professores, para assim apresentar aos participantes novos paradigmas educacionais (MALHEIRO, 2016).

O trabalho colaborativo, no referido Clube, permite uma postura investigativa de elevação do status no planejamento de Sequências de Ensino Investigativo (SEI), passando de desenvolvimento de atividades optativas para uma necessidade de aprender fazendo e fazer para aprender. Nesse Clube, não se considera que se tenha um método científico na construção do conhecimento, uma vez que as etapas da SEI e raciocínios são 
valorizados, procurando mudar a cultura experimental - de uma experimentação espontânea (conceitos intuitivos ou cotidianos) a uma experimentação científica. Criando, assim, condições para que os professores e alunos, social e individualmente, construam o conhecimento que se deseja ensinar (CARVALHO, 2013).

A experimentação investigativa adotada no Clube está ligada a inovações na avaliação, pois se exige uma nova postura, no sentido de inclusão de todos os participantes (professores e alunos), caso contrário, torna-se inconsistente. A avaliação é organizada durante todo o processo formativo de SEI, adotado no Clube.

A concepção das atividades desenvolvidas no Clube é de por as "mãos na massa" (MALHEIRO, 2016, p. 109). Nas etapas que norteiam a experimentação investigativa, é importante destacar que tal atividade não se concebe propriamente como aulas de ciências, como "fada benfazeja" (CHASSOT, 2003; MALHEIRO, 2016, p. 110), para solucionar ranços, estabelecidos na educação científica, mas sim, como exploração alegre e prazerosa do mundo que nos cerca.

As SEI da experimentação adotadas no Clube são uma abordagem didática que exige do professor eficácia e domínio dos aspectos de clima, instrução, disciplina e organização na integração da atividade. O autor contempla, em certa medida, a "necessidade de formação" que propicie atualização, renovação de conhecimento, habilidades e capacidades aos professores no exercício da função (MALHEIRO, 2016, p. 22).

As etapas de ação experimental, no Clube de Ciências, estão relacionadas à aprendizagem, remetem a motivações de DPD, trata-se de um trajeto, inclui oportunidades ilimitadas para melhorar a prática formativa relacionadas com a formação docente, e opera sobre as pessoas, não sobre os programas (ROCHA \& MALHEIRO, 2017a). 


\section{Fatores motivacionais para o desenvolvimento profissional docente}

Ao longo de nosso exercício profissional docente, buscamos manter o espírito acadêmico e, dentro de suas vivências e experiências, desenvolver melhor entendimento sobre os processos de formação e aprendizagem dos profissionais da educação. Em diversas oportunidades, participando principalmente de eventos, onde experts da área discutiam suas ideias, vinham indagações como: por que a maioria das ações de formação as quais estudamos estão fadadas ao fracasso? Por que, ao voltar para o chão de sala de aula, no meu caso, a escola básica, é-se engolido pela organização do espaço escolar e por concepções de professores que sempre se recusam a atrever-se a mudar, a introduzir inovações em suas práticas cotidianas? $\mathrm{E}$ dentro deste contexto, por que manter-me com lampejos científicos de postura profissional docente, buscando também DPD?

Nesse sentido, concorda-se com Vaillant e Marcelo (2012), que independente de nossas necessidades do contexto, do ambiente, do grupo, há um fator que determina que uma pessoa aprenda ou não. Esse fator é a vontade de melhorar ou de mudar. Dessa forma, a motivação para mudar é o elemento que determina que qualquer indivíduo se arrisque a "olhar para o outro lado do espelho" (p. 31). E no surgimento e manutenção dessa motivação, assumir um papel fundamental às ilusões, aos projetos pessoais, aos outros, aos contextos vitais nos quais nos desenvolvemos e crescemos (VAILLANT \& MARCELO, 2012, p. 31).

Nos estudos de Dantas (2012), verificamos algumas características teóricas de alguns autores (KOEHLER \& RAINER, 2008; MURRAY, 1986; ROBBINS, 1999) sobre motivação. Baseados nesse estudo, podemos inferir que a motivação, basicamente, tem relação com a ação de aprendizagem, pois, por trás de toda ação, existe uma energia psíquica e biológica que impulsiona o indivíduo a agir em direção ou rejeição ao objeto.

Assim, na construção do DPD, há uma preparação para a mudança, desenvolvendo-se habilidades profissionais viáveis e, principalmente, 
motivando os professores a aprenderem e a continuarem aprendendo como as circunstâncias pessoais mudam, promovendo a capacidade de perseverar e de se autoformar. Dessa forma, a atitude mais importante que pode ser formada é o desejo de continuar aprendendo.

Para Dantas (2012), a motivação humana, dentro de uma dimensão histórica, durante muito tempo, foi estudada sob o prisma do impulso ou do instinto. As teorias contemporâneas baseiam-se na percepção social e nas perspectivas cognitivas, mudando com isso o seu foco para o comportamento dos seres humanos diante de fenômenos sociais. De forma resumida, de acordo com as sínteses teóricas sobre motivação, podemos inferir que a motivação, basicamente, tem relação com a ação.

Entende-se que os sujeitos professores deste trabalho buscam DPD, motivados por suas energias, diante de conflitos sociais e estruturais. Mesmo diante da desvalorização e de não ter uma remuneração digna de sua responsabilidade, devem ter alguma autoestima para que estejam motivados ao desenvolvimento profissional.

Com a organização do espaço escolar e das propostas pedagógicas de cursos de formação de professores, dentro da racionalidade técnica, dificilmente iremos melhorar a qualidade formativa. Entender a motivação e os interesses que fazem os professores investirem na profissão diante dessa realidade constitui um "elemento essencial à própria razão de ser do professor" (MOREIRA, 1997, p. 1). 
Nesse contexto, apresentamos um mapa conceitual (Figura 1) que sintetiza as principais teorias de motivação de aprendizagens (ISLAS, 2014), que se associam ao DPD, que trazem fatores de responsabilidade pessoal e profissional, o que determina a capacidade e envolvimento de aprendizagem

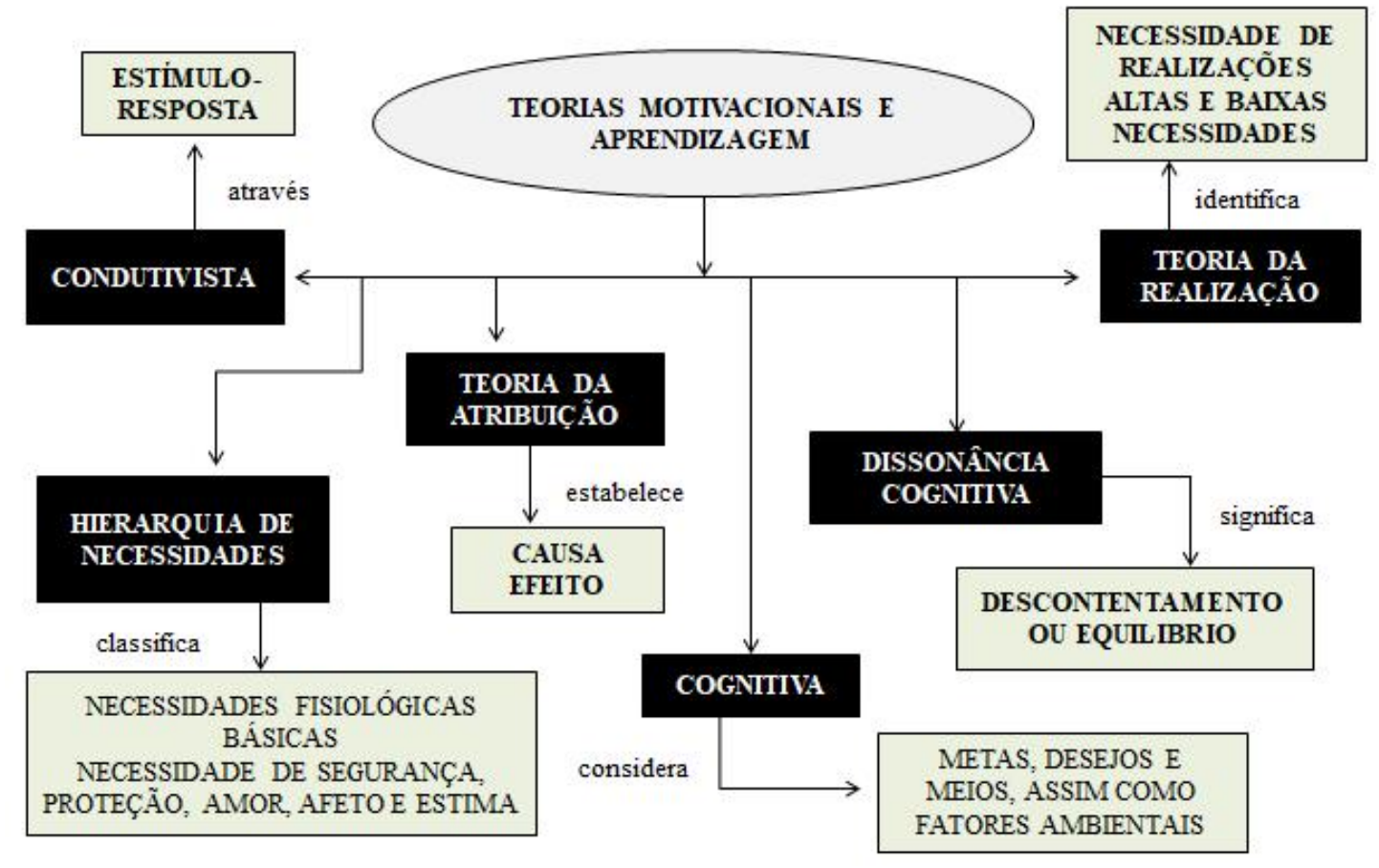

dos professores.

Figura 1: Mapa conceitual de teorias motivacionais de aprendizagem.

Fonte: Com base em Islas (2014). Nossa tradução.

Podemos inferir, dentro das teorias motivacionais de aprendizagem (ISLAS, 2014), que o que está presente em todos os enfoques é a autonomia do adulto em aprender. Essa autonomia na aprendizagem é definida por Vaillant e Marcelo (2012, p. 37) como "a capacidade relativa de participar de forma produtiva nas diferentes experiências de aprendizagem".

Para os autores, as pessoas adultas se movem entre dois polos opostos possiveis e um intermediário. De um lado, existe o que denomina a "dependência disfuncional do aprendiz", caracterizada pela incapacidade ou falta de motivação para empreender uma aprendizagem, sem estar dirigido por outros. No polo oposto, estariam as pessoas caracterizadas por uma "independência disfuncional do aprendiz", entendida como a incapacidade ou a falta de motivação para aceitar ajuda ou orientação de qualquer tipo 
nos processos de aprendizagem. Entre um extremo e outro, situa-se a possibilidade de "autonomia funcional do aprendiz", entendida com a capacidade e a motivação para participar da seleção e experimentação de aprendizagem nas quais a pessoa possa avançar sozinha ou em contato com outras (VAILLANT \& MARCELO, 2012, p. 38).

Dantas (2012) ainda complementa que alguns trazem como tônica a ação motivada e voltada para o crescimento e as competências individuais, colocando o indivíduo como o principal protagonista do seu comportamento diante do mundo. Diante de seus estudos, a autora conceitua motivação como sendo uma energia psíquica que está canalizada para a eliminação de necessidades e alcance dos objetivos pessoais, baseando-se nos conteúdos individuais (conhecimento e afetividade), percepções, vivências e contexto vivido, o que também se entende como essenciais para o DPD.

As teorias sobre motivação não se esgotam com os autores citados. Os estudos vêm evoluindo e voltando-se para os conteúdos, percepções e vivências individuais como base para a motivação. Apesar de ser encontrado um vasto repertório teórico sobre motivação, pensando na construção desta pesquisa, enfatizaram-se reflexões que partem da determinação das necessidades humanas, caracterizadas por identificar os diferentes tipos de necessidades, permitindo a descrição de razões e desejos relacionados à motivação.

Nesse entendimento, os fatores motivacionais são entendidos, nesta pesquisa, como situações mobilizadoras que estimulam a energia de ação e motivação dos professores para o DPD, o que provoca atitudes.

Diante disso, a motivação de professores para aprender, quanto à compreensão relativa às interações entre eles e o ambiente de DPD, poderá ser analisada por meio da autonomia dos que aprendem. Vislumbra-se, nesta autonomia, um importante suporte para avaliar a motivação de professores em contextos especificos de aprendizagem em comunidades com postura investigativa. Para que isso fique mais evidente, necessita-se, inicialmente, de um maior entendimento dessa autonomia, assim como do rendizado e desenvolvimento individual. 
Vaillant e Marcelo (2012) concebem que o ambiente e a pessoa interagem em um processo contínuo, no qual se podem observar diferentes níveis de autonomia nos sujeitos em função das características pessoais e contextuais. No caso dos sujeitos que aprendem, Long (1988) faz a utilização de dimensões de controle psicológico e pedagógico para descrever diferentes situações, em função das possibilidades de autonomia (Figura 2).

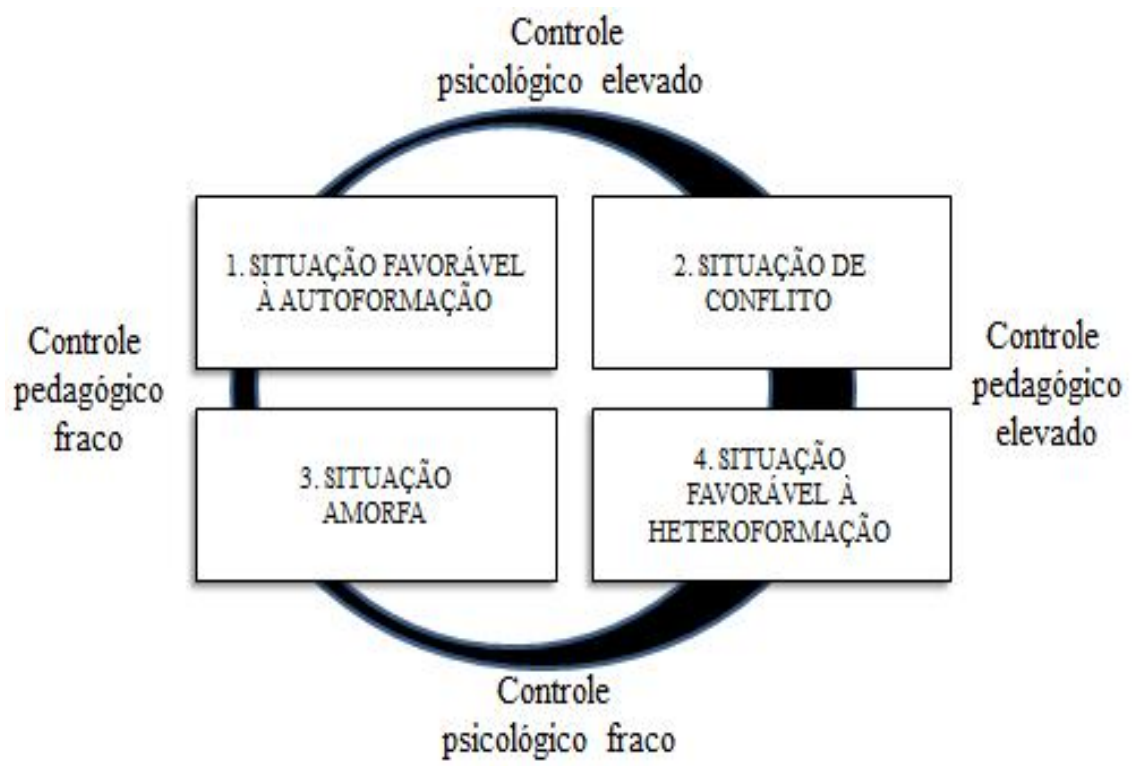

Figura 2: Autonomia dos que aprendem

Fonte: O autor com base em Vaillant e Marcelo (2012) e Long (1988). Adaptado.

Existe uma primeira situação, na qual o controle pedagógico é deficiente, mas o controle psicológico da pessoa é elevado, e é essa situação que permite a autoformação. A autoformação é uma formação na qual o individuo participa independentemente e tem sob seu controle os objetivos, os processos, os instrumentos e os resultados da própria formação. A heteroformação se organiza e se desenvolve "de fora", por especialistas, sem que seja comprometida a personalidade do sujeito que dela participa (VAILLANT \& MARCELO, 2012, p. 30). Ambas são importantes para os processos de formação de adultos.

No lado oposto, estaria a situação favorável à heteroformação, na qual a pessoa cede o controle de seu processo de aprendizagem a formadores ou a instituições. Outras combinações geram situações, nas quais se podem produzir conflitos, caso os sujeitos não assumam as formas de organização 
pedagógica das quais participa. A situação três seria extrema e submetem-se a pessoas com pouca capacidade e autonomia pessoal

Entende-se, nesse ponto de vista, a autonomia como algo pré-existente e como o resultado de um sistema, algo que deve ser elaborado, preservado e desenvolvido como uma característica da identidade individual. Assim, a autonomia não deve ser entendida fora do contexto que a gera (VAILLANT \& MARCELO, 2012). Como comenta os autores, "ser autônomo significa ser responsável por si mesmo em um ambiente no qual participam outros sujeitos autônomos" (p. 38).

Assim sendo, consideram-se os fatores de motivação responsáveis pelo início, persistência e término de determinado comportamento. Enquanto que a autonomia, dentro da abordagem de autodeterminação, até aqui concebida, pode ser considerada um elemento central à vontade, à autoiniciativa e à autorregulação integradoras para o desenvolvimento profissional.

\section{Elementos teóricos metodológicos}

Este trabalho se desenvolveu dentro da abordagem qualitativa (MELLO \& CUNHA, 2010; STRAUSS \& CORBIN, 2008), sob o método de estudo descritivo exploratório (COLLADO \& SAMPIERE, 2014). Assim, acreditamos que o estudo possibilita situar o fenômeno no contexto do DPD, incluindo seus fatores motivacionais (DANTAS, 2012; ISLA, 2014; LAVILLE \& DIONNE, 1999) de percurso formativo e profissional na compreensão dos sujeitos pesquisados.

Para isso, selecionamos cinco mestrandos (M1, M2, M3, M4 e M5), que desenvolvem pesquisas com postura investigativa no Clube de Ciências "Prof. Dr. Cristovam Diniz", localizado na UFPA/Campus Castanhal.

Como instrumento de coleta de dados, aplicamos um questionário online. A escolha do uso da ferramenta Internet para a aplicação do instrumental deu-se pela praticidade de tempo e distância de contato. $\mathrm{O}$ questionário é composto por questões abertas relacionadas ao levantamento dos dados biográficos do respondente. A questão fechada está configurada 
em uma escala de Likert, com 15 indicadores de fatores motivacionais baseados em Laville e Dionne (1999) e Islas (2014), com cinco itens de resposta, entre concordo e discordo, que mobilizam o profissional ao DPD.

Após delimitarmos as frequências para os indicadores, realizamos o processo de análise em duas categorias: Perfil dos professores e Fatores motivacionais. No quadro de itens de Likert, o tratamento teve que ser de forma mais aperfeiçoada, de modo a separar indicadores como seis tipos de fatores motivacionais. Combinamos a análise de construção de dados à teoria fundamentada nos dados - Groundt teory (MELLO \& CUNHA, 2010; SANTOS, et al., 2016).

\section{Resultados e discussões}

Com o intuito de permitir maior objetividade na apresentação dos dados, optamos por dividir a apresentação destes, contemplando duas categorias: perfil dos professores e fatores motivacionais. Os fatores motivacionais foram subdivididos em: (1) Pessoal; 2) Profissionalidade e Prática Docente; 3) Empregabilidade; 4) Salarial; 5) Complemento da Formação Inicial; e 6) Incentivo. Tal organização contribui para melhor descrição e compreensão dos resultados.

\section{Perfil dos professores}

A pesquisa foi realizada no mês de janeiro de 2018 e teve, como respondentes, cinco alunos de mestrado da UFPA. Acrescentamos ainda que, desses respondentes considerados para o estudo, todos possuem licenciatura plena, conforme quadro 1 . Nesse caso, temos basicamente um grupo de respondentes (Quadro 1) composto de professores com licenciatura plena (LP) em biologia (M1), em química (M2, M3 e M4) e em educação fisica/pedagogia (M5).

Quadro 1: Perfil dos sujeitos pesquisados

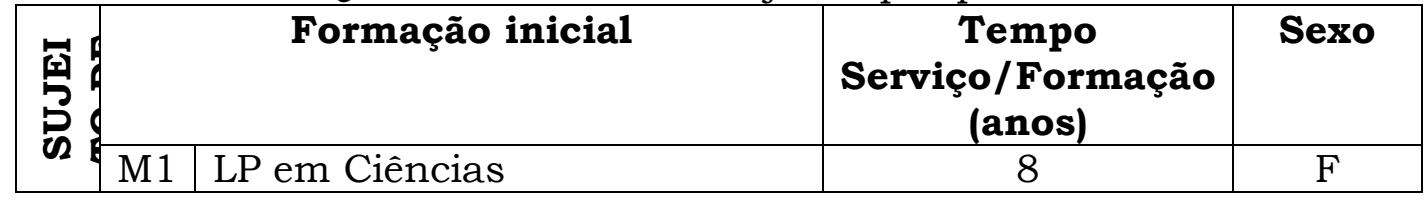




\begin{tabular}{|c|c|c|c|c|}
\hline & \multicolumn{2}{|c|}{ Naturais/Biologia } & & \\
\hline M2 & \multicolumn{2}{|c|}{$\begin{array}{l}\text { LP em Ciências } \\
\text { Naturais/Química }\end{array}$} & 9 & M \\
\hline M3 & \multicolumn{2}{|c|}{$\begin{array}{l}\text { LP em Ciências } \\
\text { Naturais/Química }\end{array}$} & 4 & $\mathrm{~F}$ \\
\hline M4 & \multicolumn{2}{|c|}{$\begin{array}{l}\text { LP em Ciências } \\
\text { Naturais / Química }\end{array}$} & 4 & M \\
\hline M5 & \multicolumn{2}{|c|}{$\begin{array}{l}\text { LP em Educação Física/LP em } \\
\text { Pedagogia }\end{array}$} & $14 / 4$ & $\mathrm{~F}$ \\
\hline \multicolumn{2}{|c|}{$\begin{array}{l}\text { Idade } \\
\text { (anos) }\end{array}$} & $\begin{array}{l}\text { Renda Mensal } \\
\text { (salários minimos) }\end{array}$ & \multicolumn{2}{|c|}{$\begin{array}{c}\text { Trabalha } \\
\text { Atualmente/Instituição }\end{array}$} \\
\hline M1 & 33 & Mais de 2 a 4 & \multicolumn{2}{|c|}{ Sim/Escola Pública Estadual } \\
\hline M2 & 35 & Mais de 2 a 4 & \multicolumn{2}{|c|}{ Sim/Escola Pública Estadual } \\
\hline M3 & 30 & Sem renda & \multicolumn{2}{|c|}{ Não } \\
\hline M4 & 49 & Mais de 2 e 4 & \multicolumn{2}{|c|}{ Não (aposentado) } \\
\hline M5 & 36 & Mais de 6 a 8 & \multicolumn{2}{|c|}{$\begin{array}{c}\text { Sim/Escola pública } \\
\text { Estadual/Municipal }\end{array}$} \\
\hline \multicolumn{5}{|c|}{ Cursos concluidos após Formação Inicial (mais de 40hs) } \\
\hline M1 & \multicolumn{4}{|c|}{$\begin{array}{l}\text { Especialização em saúde e ciências socioambientais/Curso } \\
\text { Educação do Campo. }\end{array}$} \\
\hline M2 & \multicolumn{4}{|c|}{$\begin{array}{l}\text { Especialização em educação ambiental/Libras e direitos } \\
\text { humanos. }\end{array}$} \\
\hline M3 & \multicolumn{4}{|c|}{ Curso Técnico em informática/Curso Libras. } \\
\hline M4 & \multicolumn{4}{|c|}{ Prática de ensino. } \\
\hline M5 & \multicolumn{4}{|c|}{$\begin{array}{l}\text { Especialização em educação física escolar/Especialização em } \\
\text { Gestão e Coordenação pedagógica/Especialização em } \\
\text { Educação para relações étnicas raciais. }\end{array}$} \\
\hline
\end{tabular}

Fonte: Os autores.

Nesta pesquisa, identificamos que a média de idade dos professores pesquisados é de 36,5 anos, com tempo de formação compreendido entre 4 e 14 anos. Dos sujeitos da pesquisa, três são mulheres (M1, M3 e M5). Os sujeitos M1, M2 e M5 encontram-se em atividade econômica com renda de 2 a 4 salários mínimos; os respondentes M1, M2 e M4 têm vínculo em apenas uma escola pública estadual; já o sujeito M5, tem renda de mais de 6 a 8 salários mínimos, com vínculo municipal e estadual; e o entrevistado M3 não possui nenhuma renda salarial.

As médias salariais inferem uma jornada de 40 horas semanais de trabalho. Essa remuneração pode estar relacionada ao tempo de serviço e ao tempo de formação, fatores que influenciam na escala salarial, o que faz com que tal renda não seja baixa, considerando a realidade brasileira. Nessa 
relação entre salário e tempo de serviço, observa-se que o mais alto salário médio é pago ao profissional com maior tempo de serviço e com mais de um vínculo empregatício.

Podemos inferir que, apesar do M3 e M4 não possuírem vínculo docente/rendimentos, o sujeito M3 está na fase de estabilização, que requer sentimento de competência, pertença a um corpo profissional; e M4, apesar de estar em fase de desinvestimento na carreira, ainda possui serenidade em buscar DPD. M1 e M2 encontram-se na fase de "estabilização" e M5, com maior tempo de atuação, mais cursos concluídos após a formação inicial e melhores vencimentos, na fase de "diversificação e questionamento", que sugere um momento de motivação, busca de novos desafios e reflexões sobre a carreira (HUBERMAN, 2000).

Os resultados inferem um sentimento de preocupação com os avanços na profissão, marcado por uma atitude geral de mudança e ativismo, bem como uma atitude de revisão, cheia de interrogações peculiares da carreira. Portanto, destaca-se o esforço desses profissionais em ampliar seus conhecimentos, pois além da baixa ou nenhuma renda, em sua maioria, conseguem trabalhar e estudar, demonstrando com isso certo esforço e autonomia para conseguir avançar em seu DPD.

Percebemos, nos professores, que, após concluírem a formação inicial, buscaram seu DPD através especializações lato sensu e cursos de curta duração, como educação do campo, informática e libras, gestão e relações étnicas raciais. A preocupação com o aperfeiçoamento profissional reflete o DPD, diversificando suas áreas específicas.

Em concordância com Vaillant e Marcelo (2012), dentro de um processo de mudança social e educativa, transforma-se, sem dúvida alguma, ainda mais o trabalho dos professores, sua formação e também a valorização que a sociedade faz de seus trabalhos. Os resultados identificam que os professores demonstram preocupações, no sentido de que suas ações formativas se tornem mais interessantes e dinâmicas, possibilitando um ambiente ativo de profissionalidade. 


\section{Fatores Motivacionais}

Conforme explicado na metodologia aplicada, que orienta este trabalho (DANTAS, 2012; LAVILLE \& DIONNE, 1999; MELLO \& CUNHA, 2010; SANTOS et al., 2016), na qual está baseado o questionário proposto, com o qual se realizou a coleta de dados, existe uma questão fechada com 15 indicadores que solicitam ao respondente escolher as possibilidades, entre os 5 itens estruturados (Concordo, Concordo Parcialmente, Nem Concordo e Nem discordo, Discordo Parcialmente e Discordo), conforme o modelo de Likert, que mais se adéquam aos motivos que o levaram ao DPD, por meio do curso de mestrado. Esses resultados foram organizados nas seguintes unidades de análises:

\section{Fator Motivacional: Pessoal}

O fator motivacional denominado Pessoal (Tabela 1) refere-se às situações que, quando ocorrem, envolvem o respondente de forma a confortá-lo e satisfazer uma necessidade individual, como consequência principal para ele próprio, sem buscar relação direta com sua prática docente ou seu desejo de ampliar o conhecimento (DANTAS, 2012; LAVILLE $\&$ DIONNE, 1999). Neste sentido, obteve-se o seguinte resultado:

\section{Tabela 1: Fator motivacional pessoal}

\begin{tabular}{l|c|c|c|c|c}
\hline \multicolumn{1}{c|}{ Indicadores } & $\begin{array}{c}\text { Concor } \\
\text { do }\end{array}$ & $\begin{array}{c}\text { Concordo } \\
\text { parcialm } \\
\text { ente }\end{array}$ & $\begin{array}{c}\text { Nem } \\
\text { concordo e } \\
\text { nem } \\
\text { discordo }\end{array}$ & $\begin{array}{c}\text { Discordo } \\
\text { parcialm } \\
\text { ente }\end{array}$ & $\begin{array}{c}\text { Discor } \\
\text { do }\end{array}$ \\
\hline $\begin{array}{l}\text { Atender solicitação } \\
\text { da família }\end{array}$ & & $1 / 5$ & & $4 / 5$ \\
\hline $\begin{array}{l}\text { Prazer e satisfação } \\
\text { pessoal }\end{array}$ & $4 / 5$ & $1 / 5$ & & & $5 / 5$ \\
$\begin{array}{l}\text { Melhorar minha } \\
\text { imagem diante da } \\
\text { minha família e de } \\
\text { meus colegas }\end{array}$ & & & & & \\
\hline
\end{tabular}

Fonte: Os autores.

Conforme os indicadores, há discordância entre os professores de que suas motivações de DPD estejam relacionadas ao atendimento de solicitação 
familiar, mas concordam que é pelo prazer e satisfação pessoal. Todos discordam que o DPD seja motivado à personificação de imagem. Os resultados corroboram com a análise do quadro 1, relacionada às características da fase de evolução que marcam o processo de desenvolvimento da profissão docente.

Com esses dados, percebemos que, apesar de os participantes da pesquisa (M1, M3 e M5) serem mulheres/professoras, e que, supostamente estariam mais voltadas para a satisfação própria e da família, os professores pesquisados concebem que questões voltadas para satisfação pessoal têm maior importância em seu DPD.

\section{Fator Motivacional: Profissionalidade e Prática Docente}

Os dados indicaram que todos os professores buscam o DPD, guiandose por ampliação e atualização de conhecimentos, bem como para a busca de melhor qualificação de práticas pedagógicas. Observa-se que há uma concordância parcial (1/5) quanto à motivação em relação a facilitar o processo de aprendizagem para aluno (tabela 2).

Tabela 2: Fator motivacional profissionalidade e prática docente

\begin{tabular}{l|c|c|c|c|c}
\hline \multicolumn{1}{c|}{ Indicadores } & $\begin{array}{c}\text { Concor } \\
\text { do }\end{array}$ & $\begin{array}{c}\text { Concord } \\
\text { o } \\
\text { Parcialm } \\
\text { ente }\end{array}$ & $\begin{array}{c}\text { Nem } \\
\text { concordo e } \\
\text { nem } \\
\text { discordo }\end{array}$ & $\begin{array}{c}\text { Discordo } \\
\text { parcialm } \\
\text { ente }\end{array}$ & $\begin{array}{c}\text { Discor } \\
\text { do }\end{array}$ \\
\hline $\begin{array}{l}\text { Ampliar meus } \\
\text { conhecimentos }\end{array}$ & $5 / 5$ & & & & \\
\hline $\begin{array}{l}\text { Atualizar o } \\
\text { conhecimento }\end{array}$ & $5 / 5$ & & & & \\
\hline $\begin{array}{l}\text { Qualificar minha } \\
\text { prática pedagógica }\end{array}$ & $5 / 5$ & & & & \\
\hline $\begin{array}{l}\text { Facilitar o processo } \\
\text { de aprendizagem do } \\
\text { aluno }\end{array}$ & $4 / 5$ & $1 / 5$ & & & \\
\hline
\end{tabular}

Fonte: Os autores.

Esses resultados, em complemento ao que Almeida (1999) e Alarcão (1998) sugerem como conceitos de profissionalidade, consideram o tema como a adequação que é provocada pelo professor em resposta às exigências 
de sua profissão. Ainda lembra Almeida (1999) que o docente "tem uma responsabilidade especial sobre sua atuação" (p. 104).

Nesse contexto, concorda-se com Nóvoa (1997) que a profissionalização é um processo através do qual os trabalhadores melhoram seu estatuto, elevam seus rendimentos e aumentam o seu poder de autonomia. Numa relação direta, a profissionalização, para os professores, corresponde ao seu status quo, sua posição na sociedade, a partir das políticas públicas a eles direcionadas (ROCHA \& MALHEIRO, 2017b).

Ampliando essa análise, os autores destacam que a profissionalização no magistério está ligada diretamente às políticas públicas educacionais, ao contexto histórico vigente, e à valorização da profissão docente pelas politicas sociais. A profissionalização melhora a autonomia intelectual do professor.

\section{Fator Motivacional: Empregabilidade}

A empregabilidade é um tema extremamente dinâmico e a lista de prérequisitos necessários para ser desejado pelo mercado cresce continuamente em tempos de crise, os quais o país atravessa. As chamadas competências essenciais vão se tornando mais amplas e complexas à medida que o tempo passa.

Dessa forma, o desejo do professor de possuir um melhor perfil curricular, mais atrativo para o mercado de trabalho, é o que pode permitir melhor empregabilidade. O termo difere das características de profissionalidade, por estar voltado para o mercado de trabalho e não diretamente para solução de problemas em sua prática cotidiana em sala de aula (DANTAS, 2012).

A Tabela 3 demonstra os resultados nesta unidade de análise:

Tabela 3: Fator motivacional empregabilidade

\begin{tabular}{l|c|c|c|c|c}
\hline \multicolumn{1}{|c|}{ Indicadores } & $\begin{array}{c}\text { Concor } \\
\text { do }\end{array}$ & $\begin{array}{c}\text { Concord } \\
\text { o } \\
\text { parcialm } \\
\text { ente }\end{array}$ & $\begin{array}{c}\text { Nem } \\
\text { concordo e } \\
\text { nem } \\
\text { discordo }\end{array}$ & $\begin{array}{c}\text { Discordo } \\
\text { parcialme } \\
\text { nte }\end{array}$ & $\begin{array}{c}\text { Discor } \\
\text { do }\end{array}$ \\
\hline $\begin{array}{l}\text { Ampliar meu nivel de } \\
\text { escolaridade para }\end{array}$ & $3 / 5$ & $1 / 5$ & & $1 / 5$ & \\
\hline
\end{tabular}




\begin{tabular}{l|l|l|l|l}
\hline $\begin{array}{l}\text { seguir carreira } \\
\text { acadêmica } \\
\text { (Doutorado) }\end{array}$ & & & & \\
\hline $\begin{array}{l}\text { Melhorar o meu } \\
\text { curriculo e com isso } \\
\text { minha }\end{array}$ & & & & \\
$\begin{array}{l}\text { competitividade no } \\
\text { mercado de trabalho, } \\
\text { conhecer } \\
\text { profissionais de }\end{array}$ & $5 / 5$ & & & \\
$\begin{array}{l}\text { outras áreas das } \\
\text { ciências diferente da } \\
\text { minha formação. }\end{array}$ & $4 / 5$ & & & \\
\hline $\begin{array}{l}\text { Melhorar minha } \\
\text { competitividade em } \\
\text { concursos públicos }\end{array}$ & $4 / 5$ & & & \\
\hline $\begin{array}{l}\text { Melhorar minha } \\
\text { qualificação para } \\
\text { exercer outros cargos }\end{array}$ & $4 / 5$ & & & \\
\hline $\begin{array}{l}\text { Solucionar problemas } \\
\text { especificos na prática } \\
\text { profissional }\end{array}$ & $4 / 5$ & & & \\
\hline
\end{tabular}

Fonte: Os autores.

Todos os professores concordam que a relação de DPD com a empregabilidade é motivada, principalmente, pela associação curricular e competitividade no mundo do trabalho, com trocas de experiências com profissionais de outras áreas. Ainda que esta motivação esteja associada à ampliação do nível de escolaridade, à competitividade e à qualificação, possibilitando o exercício de outros cargos e a solução de problemas profissionais, os professores compreendem a importância de DPD para o mundo do trabalho.

Apenas $1 / 5$ dos professores discordam parcialmente de que a motivação esteja relacionada à ampliação do nível de escolaridade, uma vez que, nesta pesquisa, há um sujeito (M4) na fase de recuo e interiorização do processo evolutivo da profissão docente.

Assim, os professores pesquisados, ao participarem do curso de mestrado, além de concordarem em dar continuidade à formação, estão motivados a melhorarem sua prática profissional e também sua empregabilidade. A principal motivação relacionada à empregabilidade é 
poderem melhorar seus currículos e ampliarem suas áreas específicas colaborativamente. Percebe-se alguma dúvida em relação a ocuparem outros cargos ou a solucionarem problemas específicos na prática profissional. Nesse sentido, para Saviane (1997, p. 29), é necessário termos uma postura de "não mais parar" de aprender. Para o autor, o termo deve ser entendido como sendo uma melhoria continua do conhecimento, das habilidades e do comportamento, conforme concebe esta pesquisa.

\section{Fator Motivacional: Salarial}

Para esta categoria de análise, foi selecionado o item: melhorar meu salário, a questão mobilizadora destes professores buscarem o DPD através do mestrado. Para esse fator, identificou-se, conforme a Tabela 4, que há uma leve discordância $(1 / 5)$ de o professor ampliar seu DPD, com interesse na melhoria salarial.

Tabela 4: Fator motivacional salarial

\begin{tabular}{l|c|c|c|c|c}
\hline \multicolumn{1}{|c|}{ Indicadores } & $\begin{array}{c}\text { Concor } \\
\text { do }\end{array}$ & $\begin{array}{c}\text { Concord } \\
\text { parcialm } \\
\text { ente }\end{array}$ & $\begin{array}{c}\text { Nem } \\
\text { concordo e } \\
\text { nem } \\
\text { discordo }\end{array}$ & $\begin{array}{c}\text { Discordo } \\
\text { parcialme } \\
\text { nte }\end{array}$ & $\begin{array}{c}\text { Discor } \\
\text { do }\end{array}$ \\
\hline $\begin{array}{l}\text { Melhorar meu } \\
\text { salário }\end{array}$ & $3 / 5$ & & $1 / 5$ & $1 / 5$ & \\
\hline
\end{tabular}

Fonte: Os autores.

Considerando a renda mensal desses professores (ver Quadro 1), a busca por melhores vencimentos é legítima e possibilita maior conforto para dedicação ao DPD, uma vez que, conforme a Tabela 6, não há apoio das instituições às quais esses sujeitos estão vinculados.

A imparcialidade de um dos professores (1/5) permite uma reflexão de que, embora não seja um fator motivacional relevante, os professores demonstram autonomia para o DPD. Os participantes deixam entrever um processo de valoração dos resultados anteriores sobre empregabilidade, pautados na conquista por seus méritos e sem hipocrisias.

Assim, é importante que o professor saiba que é um artífice do nosso futuro, que deve se fazer respeitar por sua competência, que busque 
qualificação para se diferenciar e ter melhor tratamento, independente das injustiças que possam se lhe impor e que diga a si mesmo: Parabéns professor, eu vim, vi e venci.

\subsubsection{Fator Motivacional: Complemento da Formação Inicial}

Conforme Vaillant e Marcelo (2012) a história das relações entre as instituições de formação e os centros educativos que recebem docentes em formação vem se caracterizando mais pelo desencontro e pela ignorância reciproca, que por uma colaboração com benefício mútuo. Dessa forma, complementar a lacuna de conhecimento deixada pela graduação, como fator motivação para buscar DPD, é uma concordância dos participantes desta pesquisa (Tabela 5).

Tabela 5: Fator motivacional complemento da formação

\section{inicial}

\begin{tabular}{l|c|c|c|c|c}
\hline \multicolumn{1}{c|}{ Indicadores } & $\begin{array}{c}\text { Concor } \\
\text { do }\end{array}$ & $\begin{array}{c}\text { Concordo } \\
\text { parcialme } \\
\text { nte }\end{array}$ & $\begin{array}{c}\text { Nem } \\
\text { concordo e } \\
\text { nem } \\
\text { discordo }\end{array}$ & $\begin{array}{c}\text { Discordo } \\
\text { parcialm } \\
\text { ente }\end{array}$ & $\begin{array}{c}\text { Discor } \\
\text { do }\end{array}$ \\
\hline $\begin{array}{l}\text { Complementar } \\
\text { lacuna de } \\
\text { conhecimentos } \\
\text { deixada pela } \\
\text { graduação. }\end{array}$ & $4 / 5$ & $1 / 5$ & & & \\
\hline
\end{tabular}

Fonte: Os autores.

Há concordância de que o complemento da formação inicial é um fator motivacional para o DPD. Esse resultado reflete as deficiências da formação inicial, caracterizada por seu tradicionalismo, enquanto favorece um tipo de aprendizagem passivo ao estudante. Ao mesmo tempo, oferece-lhes uma perspectiva parcial do ensino, não lhes permitindo se desenvolverem.

Ressalta-se que um curso de mestrado não garante superações em relação a esse aspecto, pois também, em muitos cursos de pós-graduação, subjaz a crença de que qualquer docente pode desempenhar tarefas de formador, sem nenhum tipo de treinamento prévio. Seu saber fazer é suficiente para considerar que sabe formar. 


\section{Fator Motivacional: Incentivo}

Contemplou-se também o incentivo como fator emocional para o DPD. Apesar de não ser um impeditivo definitivo, conforme mostra a Tabela 6, os professores manifestam a necessidade de apoio, tanto da instituição em que estudam, como daquelas onde trabalham.

Tabela 6: Fator motivacional incentivo

\begin{tabular}{l|c|c|c|c|c}
\hline \multicolumn{1}{c|}{ Indicadores } & $\begin{array}{c}\text { Discor } \\
\text { do }\end{array}$ & $\begin{array}{c}\text { Concord } \\
\text { o } \\
\text { parcialm } \\
\text { ente }\end{array}$ & $\begin{array}{c}\text { Nem } \\
\text { concordo e } \\
\text { nem } \\
\text { discordo }\end{array}$ & $\begin{array}{c}\text { Discordo } \\
\text { parcialm } \\
\text { ente }\end{array}$ & $\begin{array}{c}\text { Discor } \\
\text { do }\end{array}$ \\
\hline $\begin{array}{l}\text { Aproveitar o incentivo } \\
\text { oferecido } \\
\text { instituição em que } \\
\text { estuda ou trabalho } \\
\text { (bolsa de estudo,/ }\end{array}$ & $4 / 5$ & & & $1 / 5$ & \\
liberação de carga \\
horária/outro).
\end{tabular}

Fonte: Os autores.

Dos professores pesquisados, 4/5 discordam, ainda com a mínima imparcialidade (1/5), de que o incentivo oferecido pela instituição de ensino e trabalho, atrelada ao DPD, torna necessário o apoio das instituições em que os professores estão inseridos. O incentivo dessas instituições é um fator condicionante, mas não determinante para o DPD, conforme análises anteriores.

Concorda-se com Rocha (2015, p. 99), ao afirmar que a manifestação dos professores tem servido mais para manter que para criar possibilidades de transformações no valor da profissão docente. Isso porque há diversos fatores de adversidade, situados no "mundo lá fora", ficando muito dificil lutar contra eles. Os professores pesquisados são construtores de seu próprio DPD. Há entre eles a esperança de aprender.

Destaca-se que o processo de profissionalização no magistério, como um ponto de motivação ao DPD, está ligado diretamente às políticas públicas educacionais, ao contexto histórico vigente e à valorização da profissão docente pelas políticas sociais. Dito dessa forma, parece haver um consenso 
entre os docentes de que a profissionalização do professor é construída na articulação entre a experiência e a flexibilidade de se transitar em diferentes assuntos de uma determinada área de conhecimento.

\section{Considerações finais}

Buscou-se, no presente artigo, descrever e analisar o que impulsiona os docentes a buscarem DPD e se isso tem relação com o curso de mestrado que realizam. Acrescentou-se, ainda, a importância de refletir sobre quais fatores motivadores estão envolvidos no DPD dos professores pesquisados, numa perspectiva de justaposição do que normalmente se entende por formação continuada, permitindo transformações no percurso profissional.

Destaca-se que, no Clube de Ciências, como comunidade com postura investigativa e de grupos colaborativos, os professores tecem, com autonomia, suas motivações para a sua formação, além do desenvolvimento de suas pesquisas e do crescimento profissional. Como descrito nas análises realizadas, os professores compartilham práticas de reflexão e compartilhamento no Clube.

De acordo com os resultados obtidos, a importância dos professores para a garantia da qualidade da educação é indiscutivel e, inevitavelmente, remete à motivação de permanecer na carreira docente, levando em consideração os aspectos pessoais, profissionalidade e prática docente, empregabilidade, salários, complementação da formação inicial e incentivos.

No contexto específico desses fatores motivacionais, o DPD requer a consideração às mudanças no cenário acadêmico, em decorrência das transformações sociais e políticas. Os professores devem ser responsáveis por identificar e gerir contradições, desafios, dilemas e possibilidades para profissionalização, estando atentos ao ritmo das mudanças e mantendo uma identidade e práticas pedagógicas em relação à sua atuação profissional.

Essa interferência de identidade do professor, as escutas motivacionais do que é percebido, em si mesmos e nos seus contextos de autoformação, consiste na melhor maneira de atribuirmos significado às múltiplas questões que compõem os fatores de motivação ao DPD. É sempre 
desejável que esse desenvolvimento profissional possa ser resultado do engajamento prazeroso de suas escolhas, movidas pelos sentimentos de autonomia e bem-estar.

Os resultados desta pesquisa, portanto, servem de subsídio para reflexões de fatores motivacionais e proposições de superações para potencializar o DPD. Dessa forma, respondendo à questão desta pesquisa, os professores apostam na capacidade de se organizarem em comunidades locais de estudo e investigação, mesmo sem apoio das instituições públicas e da universidade, desenvolvendo, com esforço e profissionalização, a eficácia de formação.

Ressalta-se que os resultados desta pesquisa subsidiaram uma tese, de forma a criar uma ideia a respeito do problema apresentado, e estabelecer se as motivações para DPD revelam motivos que possam contribuir efetivamente para a melhoria da profissionalidade docente e o contínuo formativo.

\section{Referências}

ALARCÃO, I. Formação continuada como instrumento de profissionalização docente. In: VEIGA, I. P. A. (Org.) Caminhos da profissionalização do magistério - Campinas: Papirus, 1998.

ALMEIDA, M. I. O sindicato como instância formadora dos professores: novas contribuições ao desenvolvimento profissional. São Paulo, 1999. Tese (Doutorado) - Feusp.

AZEVEDO, M. A. R.; CUNHA, M. I. Formação para a docência no âmbito da pós-graduação na visão dos seus formadores. Educaçao Unisinos. v. 18(1). jan/abr. p. 97-106.2014.

CARVALHO, A. M. P. O. ensino de ciências e a proposição de sequências de ensino investigativas. In: Carvalho, A. M. P. (Org.) Ensino de Ciências por Investigação: Condições para implementação em sala de aula. São Paulo: Cengage Learning, p. 1-20, 2013.

CRECCI, V. M.; FIORENTINI, D. Desenvolvimento profissional de professores em comunidades com postura investigativa. Acta Scientiae. Canoas. V15(1). p.9-23. jan/abr. 2013.

CHASSOT, A. Alfabetização cientifica: questões e desafios para a educação. Ijuí: Ed. Inijui, 2003. 
COCHRAN-SMITH, M.; LYTLE, S. L. Teacher learniing communities. Encyclopeida of Education. 2nd edition. J. Guthrie (eds.). New York: Macmillan, 2002.

COLLADO, C. F.; SAMPÍERI, R. H. Metodologia de la investigacion. Mcgraw-Hill. 5ªd. p. 656. 2014.

DANTAS, I. F. Formação continuada: um estudo sobre fatores motivacionais e a participação de professores em cursos de especialização. $118 \mathrm{f}$. Dissertação (mestrado). Escola Brasileira de Administração Pública e de Empresas, Centro de Formação Acadêmica e Pesquisa. 2012.

FIORENTINI, D.; et al. Interrelations Between teacher development and curricular change: a research program. In: BEDNARZ, N.; FIORENTINI, D.; HUANG, R. (Ed.). International Approaches to Professional development for Mathematics Teachers. Ottawa: University of Otawaa Press, 2011. v. 1, p. 213-222.

- Desenvolvimento profissional e comunidades investigativas. In: DALBEN, A; DINIZ, J.; LEAL, L.; SANTOS, L. (Org.). Convergências e tensões no campo da formação e do trabalho docente: Educação Ambiental, Educação em Ciências, Educação em Espaços não-escolares, Educação Matemática. Belo Horizonte. Autêntica. 2010. v. 1, p. 570-590.

HUBERMAN, M. O ciclo de vida profissional dos professores. In: NÓVOA, A. (Org.). Vidas de professores. 2. ed. Porto: Porto, 2000. p.31-61.

ISLAS, M. E. R. Teorías de motivación y aprendizaje. Escola preparatoria n. 2. Universidad autónoma de Hidalgo. Boletín científico Logos. v.1, n.1, jan. 2014.

KOEHLER, Michael; RAINEY, Hal G. Interdisciplinary Foundations of Public Service Motivation. In: PERRY, James L.; HONDEGHEM, A. Motivation in Public Management: the call of public service. New York: Oxford University, 2008.

LAVE, J.; WENGER, E. Situated learning: legitimate peripheral participation. New York: Cambridge University Press, 1991.

LAVILle, C.; DIONNE, J. A Construção do Saber. Porto Alegre: Artes Médicas Sul Ltda, 1999.

LONG, H. B. Self-directed learning: Application and theory. Athens, GA: Dept. of Adult Education, University of Georigia, 1988. 
MALHEIRO, J. M. S.; ROCHA, C. J. T. Clube de Ciências prof. Dr. Cristovam W. P. Diniz e o Ensino Investigativo no municipio de Castanhal (PA). EnECI - Encontro de Ensino de Ciências por Investigação. Universidade de São Paulo - USP/LaPEF-FEUSP. 2017.

Atividades experimentais no ensino de ciências: limites e possibilidades. ACTIO, Curitiba, v. 1, n. 1, p. 108-127, jul./dez. 2016.

MELlO, R. B.; CUNHA, C. J. C. A. Grounded theory. In: GODOI, C. K; MELlO, R. B.; SILVA, A. B.(Org.). Pesquisa qualitativa em estudos em estudos organizacionais: paradigmas, estratégias e métodos. $2^{\mathrm{a}}$. ed. São Paulo: Saraiva; 2010. p. 241-66.

MOREIRA, H. A Investigação da Motivação do Professor: A Dimensão Esquecida. Educação \& Tecnologia. Curitiba, v.1, p. 88 - 96, 1997.

MIZUKAMI, M. G. N.; et al. Escola e aprendizagem da docência: Processos de investigação e formação. São Carlos: EdUFSCar, 2010. 203.p

MURRAY, E.J. Motivação e Emoção. 5. ed. Rio de Janeiro: Editora Guanabara Koogan S.A., 1986.

NÓVOA, A. (Coord.). Os Professores e a sua Formação. Lisboa (Portugal): Dom Quixote, 1997.

ROBBINS, Stephen P. Comportamento Organizacional. 8. ed. Rio de Janeiro: LTC - Livros Técnicos e Científicos Editora S.A., 1999.

ROCHA, C. J. T.; MALHEIRO, J. M. S. Clube de ciências e a experimentação investigativa: estimulando a alfabetização científica de alunos no ensino fundamental. XVII ENEC - Encontro Nacional de Educação em Ciências e I SIEC - Seminário Internacional de Educação em Ciências. Escola Superior de Educação do Instituto Politécnico de Viana do Castelo. Portugal. 2017a.

.; MALHEIRO, J. M. S. Desenvolvimento profissional docente: profissionalidade, profissionalização, profissionalismo na formação stricto sensu. IX FIPED - Fórum Internacional de Pedagogia/III Seminário Nacional de Educação Básica: Educação - Resistência - Liberdade. UFPA/Campus Abaetetuba. nov. 2017b.

Ensino da quimica na perspectiva investigativa em escolas públicas do municipio de Castanhal-Pará. 2015. 120f. Dissertação (Mestrado). Universidade Federal do ABC. Santo André. São Paulo.

SANTOS, J. L. G.; et al. Perspectivas metodológicas para o uso da teoria fundamentanda nos dados na pesquisa em enfermagem e saúde. Esc. Anna Nery. 20(3). jul/set. 2016. 
SAVIANI, J. R. Empresabilidade: Como as Empresas Devem Agir Para Manter em Seus Quadros Elementos com Alta Taxa de Empregabilidade. São Paulo: Makron Books, 1997.

STRAUSS, A.; COBIN, J. Pesquisa qualitativa: técnicas e procedimentos para o desenvolvimento de teoria fundamentada. $2^{\mathrm{a}}$ ed. Porto Alegre (RS): Artmed; 2008;

VAILLANT, D.; MARCELO, C. Ensinando a ensinar: As quatro etapas de uma aprendizagem/ Denise Vaillant, Carlos Marcelo. - 1. Ed. Curitiba: Ed. UFTPR, 2012.

La identidad docente: La importância del professorado como persona. In: COLEN, M. Nuevas tendências em la formación permanente del professorado. Barcelona: Universidad de Barcelona, 2010. 